\title{
Pre-Service Science Teachers' Understanding of Chemical Multiple Representations
}

\author{
E Eliyawati $^{{ }^{*}}$, Rika Rafikah Agustin ${ }^{2}$, Rossy Andini $^{3}$ \\ \{eliyawati@upi.edu\} \\ International Program on Science Education (IPSE) Study Program, Faculty of Mathematics and \\ Science Education, Universitas Pendidikan Indonesia, Bandung, Indonesia ${ }^{1,2,3}$
}

\begin{abstract}
Chemistry deals with lots of concepts ranging from simple to more complex as well as concrete to abstract. Understanding of chemistry is needed mainly by pre-service science teachers. The purpose of this study was to investigate the understanding of preservice science teachers about chemical multiple representations at macroscopic, symbolic, and sub-microscopic levels. This study involved twenty-seven preservice science and data were collected using chemical multiple representations table. Results indicated that most of pre-service science teachers could not describe the substances when it is dissolved in water at macroscopic, symbolic, and sub-microscopic levels. A few of pre-service science teachers couldn't write correctly the symbolic level of potassium chloride. All of them couldn't write correctly the ionization reaction of acetic acid and also describe the molecular view of acetic acid solution. Generally, they had some difficulties in investigating macroscopic, symbolic, and sub- microscopic levels nor integrating these levels with the contents.
\end{abstract}

Keywords: Pre-service science teachers, macroscopic, symbolic and sub-microscopic levels

\section{Introduction}

Chemistry are all about natural phenomena such as structures, configurations, properties, and changes of matter [1]. It deals with lots of concepts ranging from simple to more complex as well as concrete to abstract [2]. Those concepts are essential to understand how nature works. Since there are a lot of abstract concepts, representation is needed to conceptualizing chemistry.

Representations is used to communicate concepts and ideas. There are three levels of it which are macroscopic, sub-microscopic, and symbolic level [3]. Macroscopic level represents chemical phenomena that can be observed by naked eye. This includes students' daily life experience [4]. Sub-microscopic level is chemical phenomena that cannot be seen by naked eye such as electron, molecule and atoms. Symbolic level is representation that uses models, figures, algebra, and computation [3]. Those three levels are called the multiple representation of chemistry [5]. With the multiple representative to help, students should build understanding of chemical phenomena while bridging what they learn in classroom and laboratory and the world in which they live in.

Considering the importance of chemistry and chemical multiple representations, it is a must for pre- service science teachers to understand all types of chemistry concepts. That is 
because in the future science teacher needs to convey the knowledge and understanding of those concepts to students. So that the student could use the concept not only to understand natural phenomena but also to solve problems. Nevertheless, previous research shows that preservice science teacher has a lot of difficulties to understand chemistry especially on submicroscopic and symbolic level since it is invisible and abstract [6]. Therefore, the purpose of this study is to investigate pre-service science teachers' understanding of chemical multiple representations at macroscopic, symbolic, and sub-microscopic levels.

\section{Method}

The method used in this study is descriptive method. By using this method, it allows the researcher to collect and describe the data collected systematically, factual, and accurate about the characteristic of the object of this study [7]. This method is appropriate since the purpose of this study is to investigate pre- service science teachers' understanding of chemical multiple representations at macroscopic, symbolic, and sub-microscopic levels. This study involved twenty-seven preservice science teachers in science education study program.

After learning about multiple representation in General Chemistry Course for one semester, the preservice science teachers are given a chemical multiple representations table that consists of four substances to be analyzed at macroscopic, symbolic, and sub-microscopic levels. In macroscopic level, they need to investigate the substances related to electricity conductivity experiment. Whether the substance is strong electrolyte, weak electrolyte, or nonelectrolyte. In symbolic level, Tservice science teacher has to write the chemical formula including the phase and the ionization reaction if there is one. In sub-Sub- microscopic level, they have to investigate the molecular view of substance. The participants investigate four substances which are two strong electrolytes, a weak electrolyte, and a nonelectrolyte. The substances were potassium chloride, hydrochloric acid, acetic acid, and sugar. All the substances are dissolved in water.

\section{Result and Discussion}

Pre-service science teacher's understanding of chemical multiple representation has analyzed by using chemical multiple representations table consisting four substances which are potassium chloride solution, hydrochloric acid solution, acetic acid solution, and sugar solution. The analysis result can be seen in Table 1 .

Table 1. Pre-service Science Teacher's Understanding of Chemical Multiple Representation Result.

\begin{tabular}{llcc}
\hline \multicolumn{2}{c}{ Chemical Multiple Representation } & \multicolumn{2}{c}{$\begin{array}{c}\text { Answer } \\
\text { incorrect }\end{array}$} \\
\hline $\begin{array}{l}\text { Macroscopi } \\
\text { c Level }\end{array}$ & $\begin{array}{l}\text { Potassium } \\
\text { chloride solution }\end{array}$ & 27 & 0 \\
& Hydrochloric acid solution & 23 & 4 \\
& $\begin{array}{l}\text { Acetic Acid } \\
\text { Solution }\end{array}$ & 27 & 0
\end{tabular}




\begin{tabular}{|c|c|c|c|}
\hline \multirow{5}{*}{$\begin{array}{l}\text { Symbolic } \\
\text { Level }\end{array}$} & Sugar Solution & 16 & 11 \\
\hline & Potassium chloride solution & 4 & 23 \\
\hline & $\begin{array}{l}\text { Hydrochloric acid } \\
\text { solution }\end{array}$ & 4 & 23 \\
\hline & Acetic Acid Solution & 0 & 27 \\
\hline & Sugar Solution & 3 & 24 \\
\hline \multirow{4}{*}{$\begin{array}{l}\text { Sub- } \\
\text { Microscop } \\
\text { ic Level }\end{array}$} & $\begin{array}{l}\text { Potassium } \\
\text { chloride solution }\end{array}$ & 8 & 19 \\
\hline & Hydrochloric acid solution & 19 & 8 \\
\hline & $\begin{array}{l}\text { Acetic Acid } \\
\text { Solution }\end{array}$ & 0 & 27 \\
\hline & Sugar Solution & 13 & 14 \\
\hline
\end{tabular}

In macroscopic level, preservice science teachers investigate the substances related to electricity conductivity experiment. They investigate whether the substance is strong electrolyte, weak electrolyte, or nonelectrolyte considering the brightness of the light and the amount of bubbles in the solution. The substances which are investigated in this study are Potassium Chloride solution, Hydrochloric acid solution, Acetic Acid solution, and sugar solution. When we categorized the substances into strong electrolyte, weak electrolyte, and nonelectrolyte, we have potassium chloride and hydrochloric acid as strong electrolyte, acetic acid as weak electrolyte, and sugar solution as nonelectrolyte [1]. The pre-service science teacher gave the correct answer when investigate the macroscopic level of potassium chloride and acetic acid solution. There are 4 preservice science teacher that take Hydrochloric acid solution as weak electrolyte (Figure 1), which is incorrect. While for sugar, 11 preservice science teachers mistook it as weak electrolyte (Figure 2). A preservice science teacher also mistook it as a strong electrolyte (Figure 3).

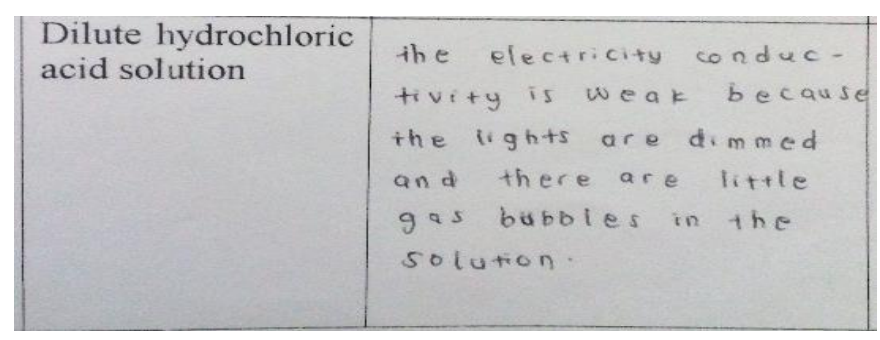

Fig. 1. Answers of $\mathrm{HCl}$ as weak electrolyte. 


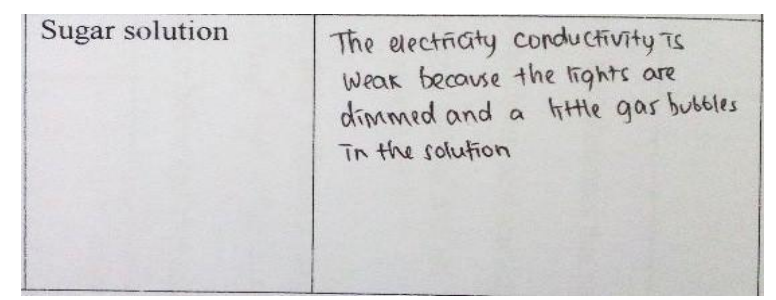

Fig. 2. Answers of Sugar as weak electrolyte.

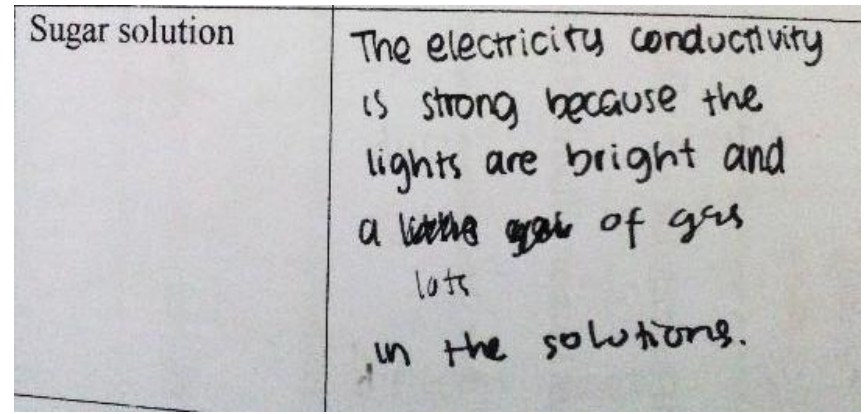

Fig. 3. Answer of Sugar as strong electrolyte.

Investigating symbolic level means preservice science teachers need to represent the substances in chemical formula including the phase. They also need to write the ionization reaction down if there is one. Since potassium chloride solution and hydrochloride solution are strong electrolytes, the substances are fully ionized. The symbolic representation of those two substances are below.

$$
\begin{aligned}
& \mathrm{KCl}(\mathrm{aq}) \rightarrow \mathrm{K}^{+}(\mathrm{aq})+\mathrm{Cl}^{-}(\mathrm{aq}) \\
& \mathrm{HCl}(\mathrm{aq}) \rightarrow \mathrm{H}^{+}(\mathrm{aq})+\mathrm{Cl}^{-}(\mathrm{aq})
\end{aligned}
$$

Regarding symbolic level of potassium chloride, twenty-three of pre-service science teachers couldn't write correctly the symbolic level of potassium chloride. Eight preservice science teachers write is as $\mathrm{CaCl}_{2}$ or calcium chloride. Four of preservice science teachers write $\mathrm{P}$ as the symbolic representative of potassium. Only four of them write the correct symbolic representative of potassium while the rest miss the ionization reaction. For Hydrochloric acid solution, there are three preservice science teachers that write it as $\mathrm{H}_{3} \mathrm{ClO}$. Two still have misunderstanding about how to symbolize solution since they write liquid (l) as solution. The rest either gave no answer or incomplete answer. Only four persons write the symbolic representative of hydrochloride acid solution correctly. They answered wrong symbolic level of subtances because they did not understand what is the chemical formula of substances.

The third substance is Acetic Acid solution. It is a weak electrolyte which means the changes is reversible [1]. The last substance is sugar. It is nonelectrolyte so there is no 
ionization reaction when sugar is dissolved. Below are the symbolic representation of acetic acid solution and sugar solution.

$$
\mathrm{CH}_{3} \mathrm{COOH}(\mathrm{aq}) \quad \rightleftarrows \quad \mathrm{CH}_{3} \mathrm{COO}^{-}(\mathrm{aq})+\mathrm{H}^{+}(\mathrm{aq})
$$

The result shows that a preservice science teacher write $\mathrm{H}_{3} \mathrm{SO}_{4}$ instead of $\mathrm{CH}_{3} \mathrm{COOH}$ for Acetic acid. The most common misconception is that acetic acid undergo irreversible reaction. All the pre-service science teachers couldn't write correctly the ionization reaction of acetic acid. There is no preservice science teacher who answer correctly. The rest either not giving any answer or give incomplete answer. For sugar solution, there are only three persons answer correctly. Most of the preservice science teacher don't write any answer and some give incorrect answer.

The last level of multiple representation that needs to be investigated is Sub-microscopic level. In this level preservice science teacher needs to represent the molecular view of Potassium Cloride solution, Hydrohloric Acid solution, Acetic Acid Solution, and Sugar solution. For Potassium Chloride solution, 8 out of 27 preservice science teacher are correctly write down the sub-microscopic representation. Four of their answer shows that Potassium Chloride is not ionized (Figure 4). The rest either don't give any anwer or give incomplete answer.

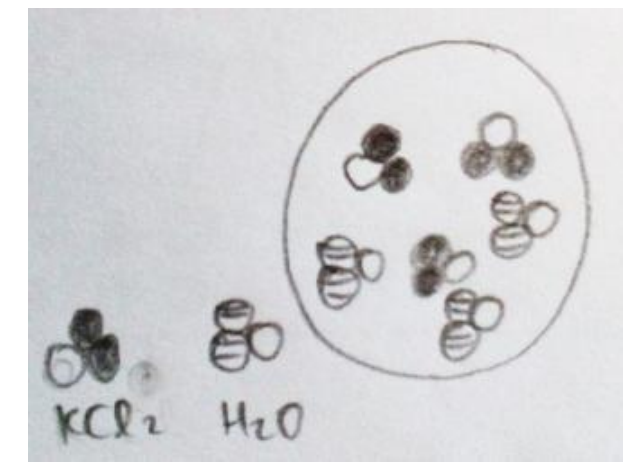

Fig. 4. Answer shows that Potassium Chloride is not ionized.

Most of the preservice science teacher give correct answer for sub-microscopic representation of hydrochloride acid solution. Only 8 of them give incorrect anwer. 4 person give no answer while 8 give incomplete answer. For Acetic acid solution all of preservice science teacher give incorrect answer. Most of them leave $\mathrm{CH}_{3} \mathrm{COOH}$ and $\mathrm{H}_{2} \mathrm{O}$. It is related to their understanding that $\mathrm{CH}_{3} \mathrm{COOH}$ is fully ionized. There is also answer that indicates Acetic acid is not ionized (Figure 5). While for sugar a preservice science teacher give sub-submicroscopic representation that shows sugar is ionized and another one shows that when sugar is dissolved all atoms of sugar is broken down (Figure 6 and Figure 7). This understanding of dissolving sugar make misconception about how molecular view of sugar. There are 13 persons who give correct anwer while the rest either give no answer or incomplete answer. 


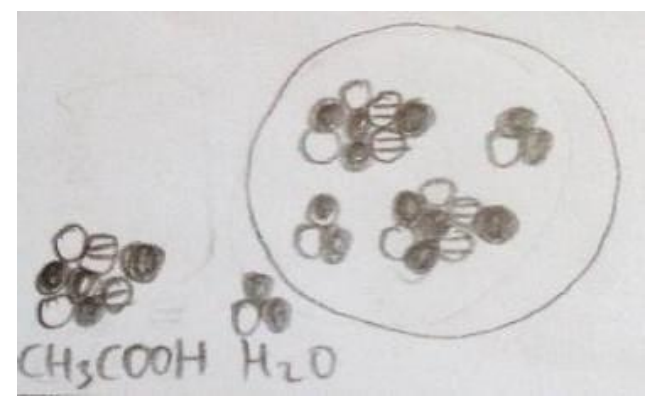

Fig. 5. Answer that shows Acetic acid is not ionized.

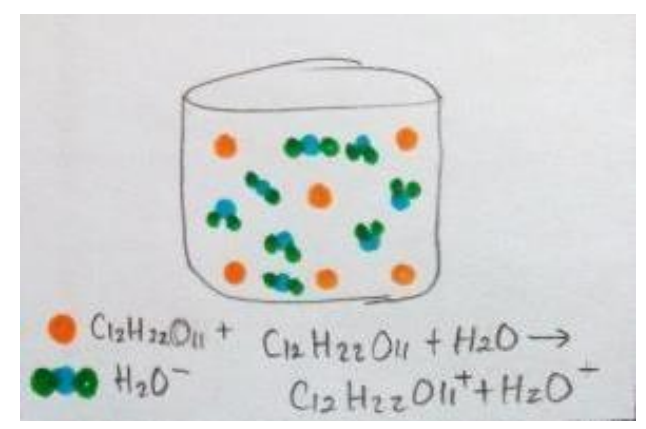

Fig. 6. Sub-microscopic representation that shows sugar is ionized given by preservice Science Teacher.

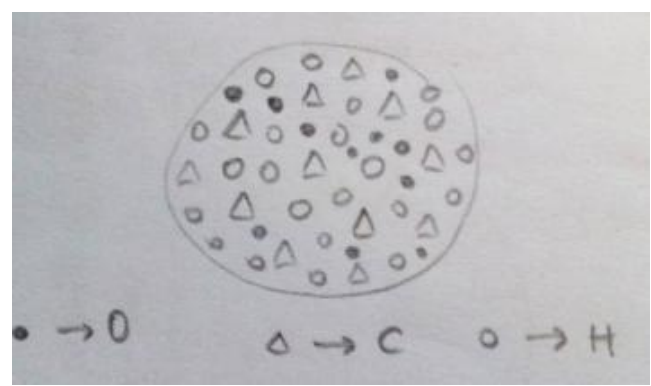

Fig. 7. Wrong answer of preservice Science Teacher about sugar when it is dissolved in water.

The pre-service science teacher understanding about chemcial multiple representation is still low especially for symbolic and sub-microscopic level. The percentage of pre-service science teacher's understanding of macroscopic level is higher than symbolic and submicroscopic level (Figure 8). They found some difficulties when write the chemical formula of substances, and analyze the molecular level of substances in solution. 


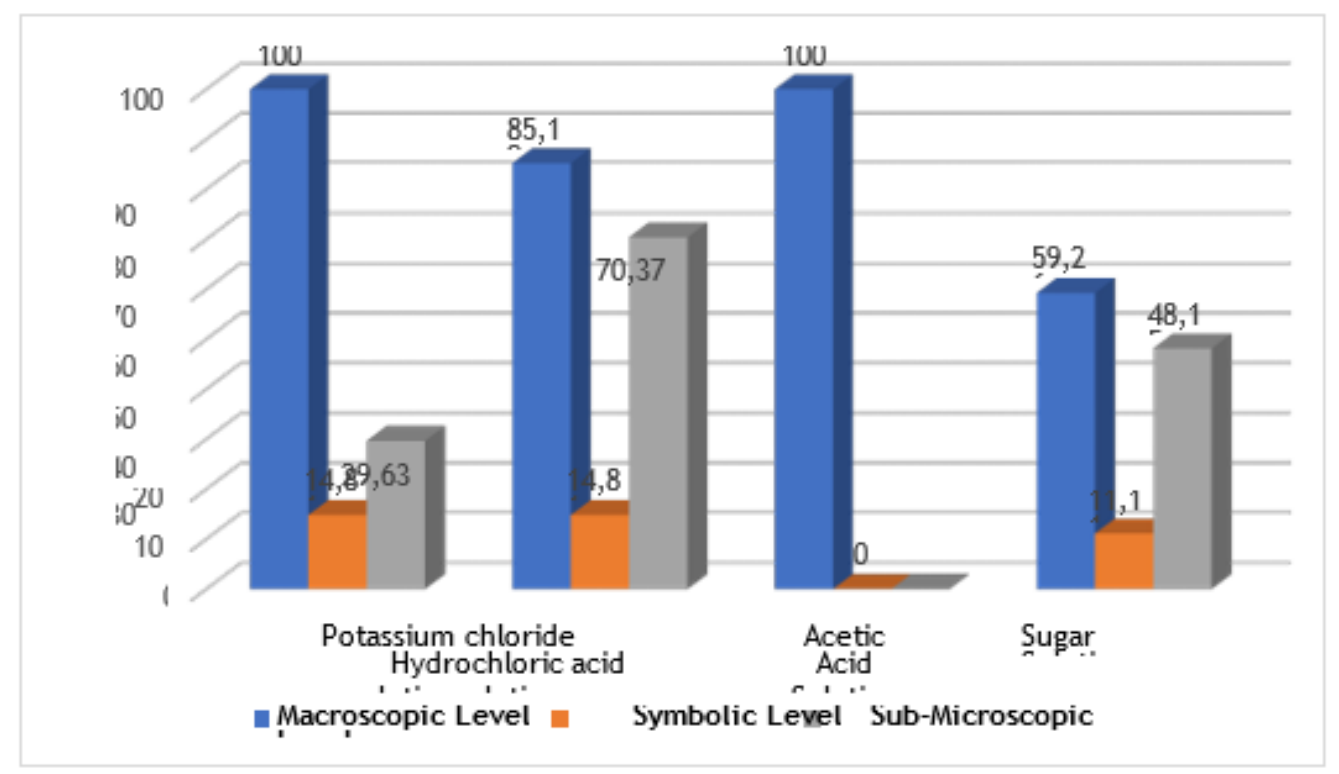

Fig. 8. The Percentage of Pre-Service Science Teacher's Understanding of Chemical Multiple Representation.

The understanding of what they have already seen when electricity conductivity experiment is important to understand the symbolic and macroscopic level of substances. The interesting thing, eventhough they understand about macroscopic level of potassium chloride and acetic acid solution, they still confuse to determine the symbolic and sub-microscopic level of those substances because they did not understand how to relate each others. The problem of misunderstanding to write the symbolic level because of they did not understand the chemical formula of certain substances. The chemical formula indicates chemical symbols to represent atoms of the elements or compound that are present [1]. The hardest thing, when the analyzed the molecular view of substances. To understand the sub-microscopic level, we need to visualize the substances because it is invisible and abstract [6]. Preservice science teachers' imagination about sub- microscopic level may vary and cannot be controlled because they have different interpretation to illustrate the molecular view of substances [8].

Data show preservice science teachers' understanding of one level will influence to understand another levels [9]. What they have already understood of the macroscopic and the submicroscopic levels depend on a context presented, in this case the kind of substances when it is dissolved in water. Preservice science teachers who can explain sub-microscopic and symbolic clearly are only a few. This result indicates they found some difficulties even though preservice science teachers were prompted to the submicroscopic and symbolic representation clearly. Another research also have the same result which explain it is very rare that students can represent sub-microscopic and symbolic clearly [10]. To enhance their understanding, helping preservice science teachers to relate the three levels chemical multiple representation is very important. So, they can understand the chemistry concept comprehensively [11]. 


\section{Conclusion}

The result shows that preservice science teachers had some difficulties in investigating macroscopic, symbolic, and sub-microscopic levels or integrating these levels with the contents. In another hand, they have to make sure that they convey the knowledge and concepts of chemistry to their students in the future. This is quite a problem that needs to be assessed and taken care. There should be ways, approach, or media that help preservice science teacher to understand chemical multiple representation. Therefore, researchers are strongly encouraged to do future research regarding this problem.

Acknowledgments. The authors would thank International Program on Science Education (IPSE) Study Program and Universitas Pendidikan Indonesia which provided opportunities and grants to participate in the MSCEIS 2019 Conference.

\section{References}

[1] N. D. J. and A. H. . E. Brady, Chemistry International Student Version 6th Edition. Asia: John Wiley and Sons, Inc, 2012.

[2] A. MR, G. EB, R. JW, and M. EA, "Understandings and Misunderstandings of 8Th Graders of 5 Chemistry Concepts Found in Textbooks," J. Res. Sci. Teach., vol. 29, no. 2, pp. 105-120, 1992.

[3] A. H. Johnstone, "Why is Science Difficult to Learn? Things are Seldom Why They Seem," J. Comput. Assist. Learn., vol. 7, pp. 75-83, 1991.

[4] D. F. Treagust, G. Chittleborough, and T. L. Mamiala, "The role of submicroscopic and symbolic representations in chemical explanations," Int. J. Sci. Educ., vol. 25, no. 11, pp. 1353-1368, 2003.

[5] V. Talanquer, "Macro, submicro, and symbolic: The many faces of the chemistry "triplet," Int. J. Sci. Educ., vol. 33, no. 2, pp. 179-195, 2011.

[6] Z. D. Roche Allred and S. L. Bretz, "University chemistry students' interpretations of multiple representations of the helium atom," Chem. Educ. Res. Pract., 2019.

[7] J. H. M. and A. Schumacher, Research in Education. New York: Addison, Wesley Longman, 2001.

[8] Eliyawati, I. Rohman, and A. Kadarohman, “The effect of learning multimedia on students' understanding of macroscopic, sub-microscopic, and symbolic levels in electrolyte and nonelectrolyte," J. Phys. Conf. Ser., vol. 1013, no. 1, 2018.

[9] Gassan Sirhan, "Learning Difficulties in Chemistry: An Overview," J. Turkish Sci. Educ., vol. 4 no. 2, pp. 2-20, 2007.

[10] S. Rahayu and M. Kita, "An Analysis of Indonesian and Japanese Students' Understandings of Macroscopic and Submicroscopic Levels of Representing Matter and its Changes," Int. J. Sci. Math. Educ., vol. 8, no. 4, pp. 667-688, 2010.

[11] D. Gabel, "Improving Teaching and Learning through Chemistry Education Research: A Look to the Future," J. Chem. Educ., vol. 76, no. 2-4, pp. 548-554, 1999. 